\title{
Glaciation and denudation rates
}

SIR - Summerfield and Kirkbride ${ }^{1}$ question the general assumption that glaciation leads to an increase in denudation rates - an assumption that they attribute to Molnar and England ${ }^{2,3}$, although this slightly overstates these authors' argument. We believe that Summerfield and Kirkbride's use of the work of Hicks et al. ${ }^{4}$ to support their thesis is inappropriate.

It is often stated that rates of erosion are higher for glacial than for nonglacial processes, typically on the basis of observations showing that sediment yields are higher in glacier-fed rivers than in comparable rivers not fed by glaciers ${ }^{5,6}$. In departing from this conventional wisdom, Summerfield and Kirkbride refer to the work of Hicks et $a l{ }^{4}$, who found no significant difference in present-day sediment yield as a function of extent of glacier cover, based primarily on data from nine small schist basins in South Island, New Zealand. Summerfield and Kirkbride imply that the apparent lack of a present-day relationship between sediment yield and percentage glacierization contradicts the assumption that an increase in glacierization over time would result in an increase in denudation rates.

Such use of present-day spatial variations as surrogates for changes that might occur over time (an ergodic assumption) is a common approach in geomorphology, yet in this case it has serious limitations. Hicks et al. ${ }^{4}$ present data for basins with $0-77 \%$ glacier cover, and it is tempting to assume implicitly that this represents a population ranging from unglaciated basins to basins in something close to full-glacial conditions (and thus to extend their conclusions to changes during glacial/interglacial cycles). Clearly this is not the case because the valleys described ${ }^{4}$ are experiencing present-day interglacial (and in some cases paraglacial) conditions. During full-glacial times, these basins would have higher percentage glacier covers, but also far greater ice thickness, discharges, velocities, basal shear stresses and basal water pressures. Regardless of which predictive model for glacial erosion one chooses ${ }^{7,8}$, it is clear that rates of glacial erosion are generally far higher during full-glacial conditions than a simple linear scaling with the change in percentage glacier cover would suggest.

Attempts to estimate current denudation rates are complicated by significant measurement errors and by an imprint of recent glacial history ${ }^{6}$ that is at present largely unquantifiable. In today's interglacial conditions it is possible that glacial erosion rates may be similar to nonglacial rates in some areas (as sug- gested in ref. 4), but present-day relationships between denudation rate and percentage glacier cover are not appropriate surrogates for changes in denudation rate over time during glacial/ interglacial cycles. At minimum it is clear that we cannot use the data in ref. 4 to refute the general idea of a positive association between periods of glaciation and enhanced denudation rates.

Department of Geology, JON HARBOR

Kent State University,

Kent, Ohio 44242, USA

Department of Geography,

University of Leicester,

Leicester LE1 7RH, UK

1. Summerfield, M. A. \& Kirkbride, M. P. Nature 355, 306 (1992).

2. Molnar, P. \& England, P. Nature 346, 29-34 (1990)

3. Molnar, P. \& England, P. Nature 355, 306 (1992).

4. Hicks, D. M., McSaveney, M. J. \& Chinn, T. J. H. Arct. Alp. Res. 22, 26-42 (1990)

5. Embleton, C. \& King, C. A. M. Glacial Geomorphology (Arnold, London, 1975)

6. Church, M. \& Slaymaker, O. Nature 337, 452-454 (1989).

7. Drewry, D. Glacial Geologic Processes (Arnold, London, 1986)

8. Shoemaker, E. M. J. Glaciol. 32, 65-71 (1986).

\section{Oscillating global temperature}

SIR - Ghil and Vautard ${ }^{1}$ applied singular spectrum analysis to a global temperature data set and claimed the existence of a 20-year oscillation corresponding to a pair of high variance empirical orthogonal functions (EOFs). Subsequently, $\mathrm{we}^{2}$ performed a sensitivity analysis considering various segments of that time series as well as of five other temperature records, and we concluded that the existence of the 20-year oscillation is questionable. We found that delineating a 20-year oscillation depends on including the (unreliable) early years of the records but not on the length of the records. Allen et al. ${ }^{3}$, using only the IPCC record, now say that when the early years are excluded, EOF4 and EOF6 exchange positions and that EOF3 and EOF6 form a 20-30-year oscillatory pair. Based on this observation, they conclude that we failed to prove our case against the 20-year oscillation.

Unfortunately, Allen et al. did not read our paper carefully. First, they say that we reported that the signature of the 20-year oscillation appears only if all 130 years are included. This is not correct. Our Fig. 3 clearly shows that, as long as the early years are included, the 20-year oscillation is present even when only 90 years are considered.

Second, Allen et al. create the impression that reproducing both Ghil and
Vautard's ${ }^{1}$ and our ${ }^{2}$ results constitutes a paradox. Ghil and Vautard considered the entire UK record, but we considered the length of that and five other records. Obtaining different answers does not therefore constitute a paradox.

Third, and most seriously, Allen et al. consider the last 110 values of the IPCC

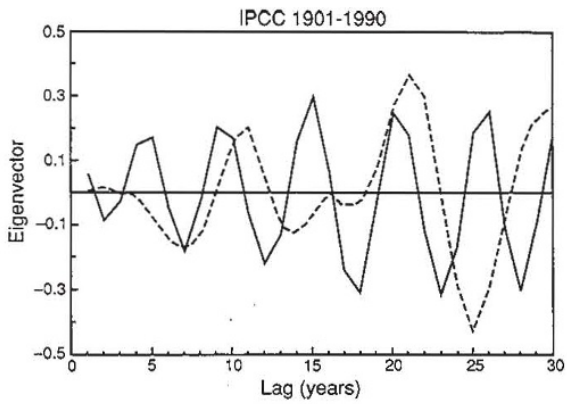

EOF3 (solid line) and EOF6 (broken line) estimated from the lag-covariance matrıx constructed from $M=30$ lagged copies of the last 90 (1901-1990) values of the IPCC consensus record of global temperature. The two EOFs do not represent oscillations of similar periodicity, and do not correspond to an oscillatory pair as Allen et al. ${ }^{3}$ suggest.

record and claim that EOFs 4 and 6 exchange places so that EOF3 and EOF6 constitute a 20-30-year oscillation. This claim is misleading. Careful examination of their figure $(b)^{3}$ reveals that EOF6 has a period of about 15 years, whereas EOF3 has a period of about 25 years. Furthermore, these two oscillations start completely out of phase with each other and end up in phase. Allen et al.'s own figure shows that EOFs 3 and 6 are not in quadrature and do not form an oscillatory pair. Thus they mislead readers by suggesting that EOFs 3 and 6 do form an oscillatory pair. They are also wrong when they claim that EOFs 4 and 6 again exchange places when the last 90 years of the IPCC record are considered, even though their figure $(a)$ indicates that the corresponding eigenvalues are not very similar. Our figure clearly shows that in this case EOF3 and EOF6 are not equal to each other, and there is no hint of a 20 -year oscillation. The limited data and the fact that the eigenvalues may not be statistically significant make Allen et al.'s conclusions questionable.

A. A. TSONIS

Department of Geosciences,

University of Wisconsin,

Milwaukee,

Wisconsin 53201, USA

J. B. ELSNER

Department of Meteorology,

Florida State University,

Tallahassee, Florida 32306, USA

1. Ghil, M. \& Vautard, R. Nature 350, 324-327 (1991).

2. Elsner, J. B. \& Tsonis, A. A. Nature $353,551-553$ (1991).

3. Allen, M. R., Read, P. L. \& Smith, L. A. Nature 355,686 (1992). 